\title{
Contribución al estudio del arte hispano antiguo: pieza con decoración orientalizante de Andalucía Occidental
}

\author{
Elena Maria Orta Garcia
}

En el verano de 1982 tuvimos ocasión de ver la pieza que vamos a dar a conocer, en la colección particular de D. Jesús Garcia de Soto, de Sevilla. Cuando le manifestamos nuestro interés por la piedra grabada que poseia, amablemente nos ofreció su publicación.

Se trata de un cono de piedra negra dura, con su parte superior redondeada que presenta una representación mitad antropomorfa, mitad zoomorfa que luego examinaremos.

La pieza se halla partida en su base y también, en parte, en su sección longitudinal.

El hallazgo habia tenido lugar pocos meses antes en Paterna del Campo (Huelva), en una finca de labor donde habia sido sacada por una máquina agrícola.

Dado el interés que ofrecia para el estudio del arte y la religión de la Península en la antigüedad, quisimos visitar el lugar del hallazgo. Se trataba de una finca de labor situada a la salida del pueblo de Paterna del Campo, entre éste y el de Escacena; el lugar ofrecia numerosos vestigios de época antigua pero no pudimos encontrar el resto de la pieza, aún cuando nos acompañó en la búsqueda la persona que la encontró. En la actualidad la pieza se encuentra depositada en el Museo de Huelva. 
Descripción. Cono de piedra dura de color negro con decoración grabada en una de sus partes y rota en su base, y en parte de su sección longitudinal. Las dimensiones son las siguientes: altura: $55 \mathrm{cms}$.; anchura máxima conservada: $11 \mathrm{cms}$.

La decoración se ha realizado con un objeto punzante presionando fuertemente la piedra y repasando los trazos varias veces para corregir las líneas. La decoración se destaca en color blanco sobre el fondo negro de la piedra.

Los motivos ornamentales son los siguientes: en la parte superior del cono una flor de loto abierta que ofrece cinco pétalos y de cuya base arrancan dos capullos de loto, uno a cada lado; por debajo de la flor aparece una figura mitad antropomorfa, mitad zoomorfa. La figura aparece partida por la mitad en sentido longitudinal, observándose un rostro que creemos femenino puesto que lleva un peinado hatórida típicamente femenino; casi inmediatamente por debajo del rostro arranca un cuerpo que parece ser de ave y un brazo humano extendido, que porta en la mano una flor de loto de cinco pétalos que se sitúa por encima de la cabeza. Presenta también un par de alas extendidas hacia la parte superior e inferior respectivamente, y una cola como puede verse en la figura 1 , y además podemos ver una reconstrucción de la figura completa, en la lámina I.

Uso. El posible uso de la pieza puede que fuese el de un cipo funerario.

Representaciones de la pieza. Tenemos en primer lugar una flor de loto, motivo de gran raigambre egipcia, y difundido ampliamente en el mundo fenicio, motivo que ya fue estudiado por Jacobsthal' ${ }^{1}$ y que aparece en el mundo oriental y en Chipre, Grecia y Etruria.

La representación figurada parece corresponder a una divinidad que ofrece un cierto sincretismo. La cabeza es femenina y lleva un peinado de rizos a los lados típicamente hatórico, y en la mano lleva una flor de loto. Estas características pueden ser interpretadas como pertenecientes a una representación de la diosa fenicia Anat o de Asherat o de Astarté.

Tiene paralelos en Oriente y es frecuente su representación en la Península Ibérica donde aparece con los mismos elementos, es decir, vista de frente, simétrica, con el mismo peinado de rizos a los lados, de carácter

\footnotetext{
1 P. JACOBSTHAL: Greek pins and their connexions with Europe and Asia, Oxford, 1956, págs. 47 y ss. Figs. 209-218.
} 
hatórico y asociada a la flor de loto que J.M. Blázquez considera representaciones de Astarté

Entre los paralelos orientales podemos señalar una serie de figurillas femeninas con peinado hatórida, con los brazos extendidos que llevan en las manos flores de loto ${ }^{3}$. Estas características las vemos también en las representaciones de la diosa siria introducida en Egipto, Qadesh, como puede verse en una estela del Museo egipcio de Turin ${ }^{4}$.

Dentro de la Península aparece en el Bronce Carriazo ${ }^{5}$, en las figurillas de Cástulo ${ }^{6}$, en el Bronce de El Carambolo ${ }^{7}$, en clavos de braserillo como los de la tumba 5 de La Joya (Huelva) ${ }^{8}$, en los remates de asas de braserillo de la tumba 18, también de la necrópolis de La Joya ${ }^{9}$ y en un relieve del monumento funerario de Pozo Moro cerca de Albacete ${ }^{10}$.

Otros de los caracteres de esta figura de Paterna del Campo es presentar un par de alas, elementos que vemos en Oriente, concretamente en unos marfiles de Nimrud ${ }^{11}$, donde se representa a la diosa Shepesh con cabeza de hathor, lotos en las manos y cuyo cuerpo es un disco con alas, una a cada lado, es decir, el disco solar alado.

Este tipo de representación de una divinidad alada la vemos también en la Península en los bronces de El Berrueco ${ }^{12}$, donde aparece la divinidad con un par de alas a los lados, el disco solar en el centro, pies, y flores de loto a los lados. La divinidad representada en la piedra de Paterna del Campo no sabemos si también llevaba en el centro una representación solar dado el estado fragmentario de la pieza.

2 J.M. Blazquez: Tartessos y los origenes de la colonización fenicia en Occidente, Salamanca, 1975, págs. 110 y ss

3 J.B. Pritchard: The Ancient Near East in Pictures, Princeton, N.J., 1969, Figs. 469, 8.30.

4 A.M. Roverl: Enciclopedia dell'Arte Antica, Clasica e Orientale, VI, pág. 583, Figs. 673.

5 J. Maluquer de Montes: “De Metalurgia Tartesia: El Bronce Carriazo", Zephyrus 8, 1957. pág. 157.

6. Blanco Freijeiro: "El ajuar de una tumba de Cástuln», Oretania 19, 1965. Figs. 19 a 22. J.M. BLAZQUez, Op. cit., pág. 111, Fig. 35. Lám. VI, 2.

B J.P. Garrido Roiz: Excavaciones en la Necropolis de "La Joya", Huelva, Madrid, 1979, págs. 28-29, Fig. 17, Lám. XVII.

¿ J.P. GarRido y E.M. OrTA: Excavaciones en la Necrópolis de "La Joya", Huelva, II, 1978 , págs. 135-138, Fig. 18a, Lám. XClll.

10 M. Almagro Gorbea: “Los relieves mitológicos orientalizantes de Pozo Moro", Trabajos de Prehistoria 35, Madrid, 1978, pág. 262, Lám. VI, 2.

"M.E.L. Mallowan: Nimrud and its remains, vol. II, Londres, 1966, pág. 497, Figs. 392394.

12 M. Almagro GorbeA: "El Bronce final y el periodo orientalizante en Extremadura", Biblioteca Prehistórica Hispana, vol. XIV, Madrid, 1977, págs. 254-255. Làm. LII, 3. 
Por todo lo expuesto creemos que la figura de Paterna se asemeja más a la de la diosa sirio-cananea Shepesh ${ }^{13}$.

En cuanto a la cronologia, hemos de tener en cuenta que su prototipo oriental de los martiles de Nimrud se datan a fines del siglo VIII a. C., pero sus paralelos peninsulares de los bronces de El Berrueco se fechan a partir del siglo vII y probablemente en el siglo vi a. de C.

La figura de divinidad de Paterna del Campo creemos que debe fecharse también, ai igual que las representaciones hatóricas, de la Península, hacia el siglo vi a. de C., o más bien a fines del siglo vII, aunque sea un tipo que perdure hasta comienzos del siglo $v$ a. de $\mathrm{C}$., como en el monumento funerario de Pozo Moro ${ }^{14}$.

En cuanto al arte, creemos que se trata de un arte hispánico que copia el arte oriental, de una manera tosca, y habriamos de incluirlo en el repertorio del arte orientalizante peninsular ${ }^{14}$ bis.

Respecto al uso funcional de la pieza de Paterna, ya hemos indicado que bien pudiera tratarse de parte de un cipo funerario.

El uso de cipos funerarios lo vemos en Etruria en donde generalmente se recubrian las tumbas de un túmulo de tierra, encima del cual se ponia un cipo o una estela.

Los cipos etruscos eran de diversas formas y se ornamentaban también con relieves; asi los vemos de forma cúbica con remate en forma de piña como uno de Settimello ${ }^{15}$, cúbico rematado con una esfera como uno de Chiusi ${ }^{16}$, de forma ovoidal como otro también de Chiusi con inscripción etrusca ${ }^{17}$ o como un cipo sepulcral de basalto negro sobre base moldurada de Orvieto $^{18}$.

La pieza objeto del presente estudio podria corresponder a la parte superior de un cipo parecido a los etruscos.

13 G.R. Driver: Canaanite Myts and Legends, Edimburgh, 1956, pág. 113.

$14 \mathrm{M}$. Almagro Gorbea: “El Monumento de Pozo Moro y el problema de las raices orientales del Arte ibérico", Rev. Las Ciencias, Madrid, tomo XL, núm. 2, 1975.

14 tis A. Blanco FreiJeiro: Orientalia. Archivo Español de Arqueologia, Madrid, 1956.

is G.Q. Giguloul: L'Arte etrusca, Milán, 1935, Tav. LXXVII, 1.

16 ldem. Op. cit. Tav. CL, 1 a 4.

17 Idem. Op. cit. Tav. CLVIII, 1.

18 Idem. Op. cit. Tav. CLVIII, 3. 


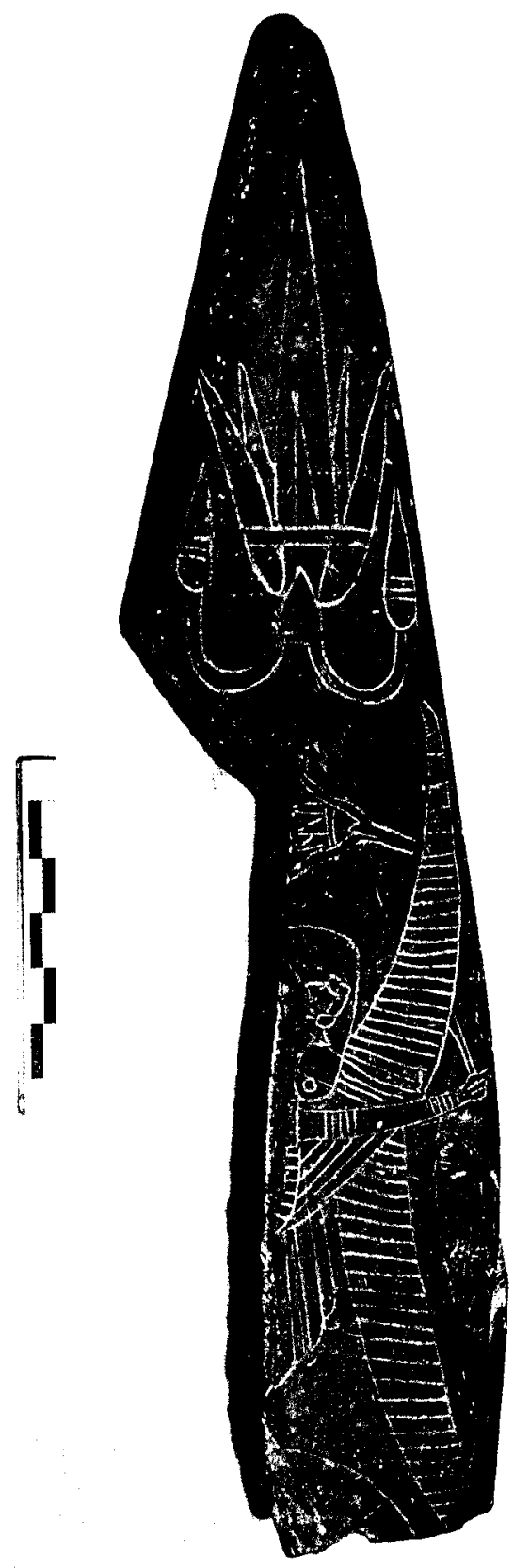

Fig. 1. Piedra con decoración grabada de Paterna del Campo (Huelva). 


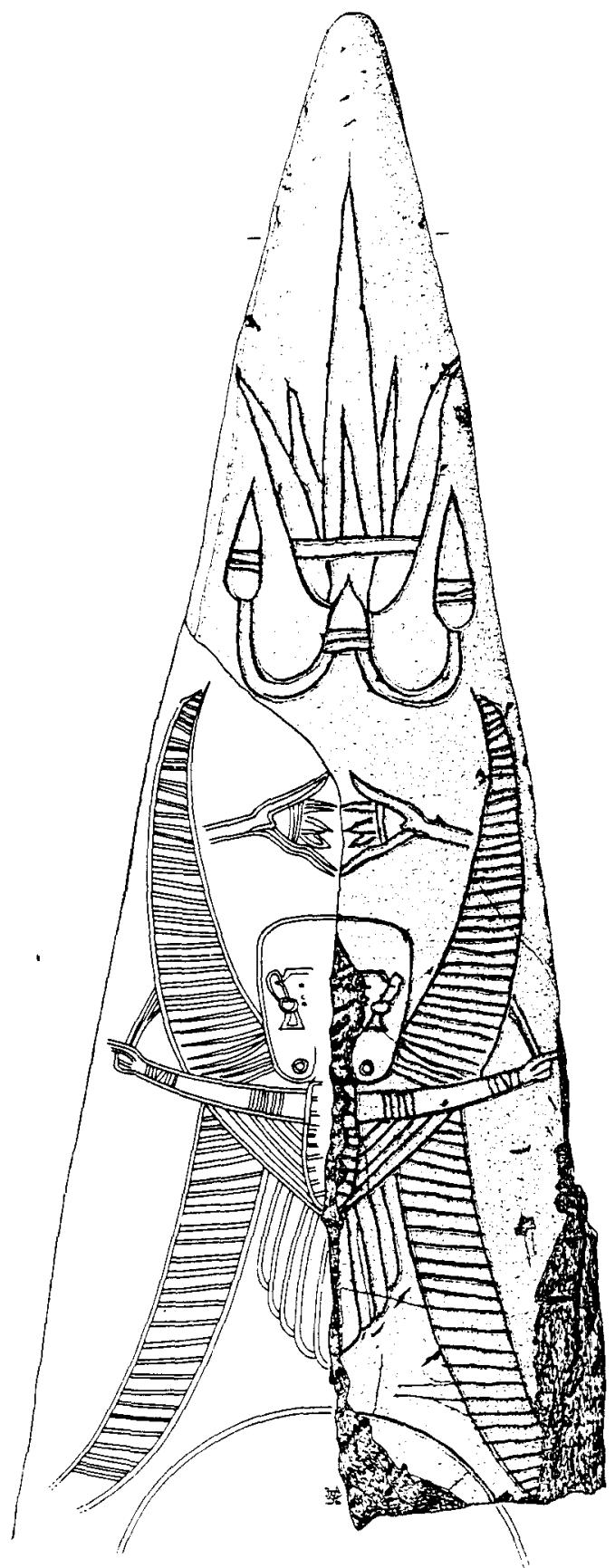

Fig. 2. Dibujo ideal completando la decoración grabada en la piedra de Paterna del Campo (Huelva). 